\title{
Initial Analysis of Plastic Debris Accumulation in the Estuary of Wonorejo River, Surabaya, Indonesia
}

\author{
Setyo Budi Kurniawan ${ }^{1,2, *}$ and Muhammad Fauzul Imron $^{3}$ \\ ${ }^{1}$ Department of Chemical and Bioprocess Engineering, Faculty of Engineering and Built Environment, Universiti Kebangsaan Malaysia, \\ 43600 UKM Bangi, Selangor, Malaysia \\ ${ }^{2}$ Department of Environmental Engineering, Faculty of Civil, Environmental and Geo Engineering, Institut Teknologi Sepuluh \\ Nopember, Kampus ITS Keputih, Sukolilo, Surabaya 60111, Indonesia \\ ${ }^{3}$ Study Program of Environmental Engineering, Department of Biology, Faculty of Science and Technology, Universitas Airlangga, \\ Kampus C UNAIR, Jalan Mulyorejo, Surabaya 60115, Indonesia
}

\begin{abstract}
The purpose of this research was to investigate the accumulation of plastic debris in the Wonorejo River Estuary, Surabaya, Indonesia. Visible plastic debris were collected from three (3) sampling points along the intertidal area of Wonorejo River Estuary. The correlation between sampling points (SPs) and the amount of the collected plastic debris (CPD) was analysed using one-way ANOVA. Result of oneway ANOVA showed that the sampling point was significantly affect the amount of the collected plastic debris $(\mathrm{p}<0.05)$. A further analysis using Tukey's Significance Honest Test indicating a significantly higher CPD on SP2 compared to the SP1 and SP3 $(p<0.05)$. The amount of CPD were $126.07 \pm 12.00 \mathrm{~g}$ dry weight $/ \mathrm{m}^{2}$ from SP1, 375.97 $\pm 16.72 \mathrm{~g}$ dry weight $/ \mathrm{m}^{2}$ from SP2, and $291.13 \pm 36.28 \mathrm{~g}$ dry weight $/ \mathrm{m}^{2}$ from SP3. The highest percentage of collected debris item was plastic bags (up to 57.90\%), followed by bottle caps (up to 16.65\%). The most identified plastic types were Low-Density Polyethylene (LDPE) (up to $73.13 \%$ ), followed by Polypropylene (PP) (up to $17.22 \%$ ). Understanding the accumulation of plastic debris in estuary is a fundamental requirement to conduct an advance research related to the marine plastic pollution and to determine further actions to solve this problem.
\end{abstract}

\section{Introduction}

Plastic is currently becoming a major global concern, especially in the marine environment [1]. Plastic in marine environment is a serious problem since many evidences are showing the existence of small plastic particles inside marine biota's body [2]. The existence of plastic particles inside the body of marine biota can also be dangerous for human health. Microplastics are very small particles of plastic that mostly found inside biota's body and tend to be trophically transferred via the food chain, thus may also harm the human health $[3,4]$.

Microplastics are tiny particles of plastic under the size of $5 \mathrm{~mm}$ [5]. It comes from two main sources, original tiny plastic products and the fragmentation of large plastic products [6,7]. Utilization of original tiny plastic particles are mostly found inside the personal care products [8]. Several countries already paid attention to these kinds of utilizations and currently banning the extensive and prolonged application [9]. After this banishment, the major source of microplastic is now turned into the large plastic item's fragmentation. This fragmentation is occurred in the environment due to the effect of environmental cracking of plastic components [10].

The cracking of plastic form smaller pieces of plastic that continually breakdown into tiny plastic particles which normally cannot be seen by bare human eyes. The evidence of microplastic existence was shown by many researchers, especially in the marine environment as the most affected ecology by the plastic pollution [11-14].

The formation of microplastic from the large plastic product fragmentation can be suppressed by preventing the entry of plastic to the marine environment [15]. It can also be carried out by avoiding the entrance of plastic to water bodies, since it will also be flowing and ended up in the ocean. In Indonesia, as one of the currently developing countries, plastic debris still can be seen flowing along the river stream [16].

Surabaya, the second largest city in Indonesia, is also facing the same plastic pollution problem. Wonorejo river, one of the big rivers in Surabaya, is sending high amount of plastic debris along its streams daily. Investigation and study related to this problem is still lacking and scattered. According to the current condition, this research was aimed to initially analyse the accumulation of plastic debris in the Wonorejo River Estuary as the first contact of Wonorejo River to the Madura Strait marine ecosystem. The presented result may highlight the distribution of several plastic types and plastic products accumulated in the estuary. The result of initial analysis can be used as a basic

Corresponding author: setyobudi.kurniawan@gmail.com 
consideration on preparing manual clean-up strategies and future regulations regarding the utilization of plastic product that pollute the estuary ecosystem the most.

\section{Materials and Methods}

\subsection{Sampling Points}

All sample were collected from 3 Sampling Points (SPs) along the sea shoreline in the intertidal area of Madura Strait that is directly connected with the estuary of the Wonorejo River. Each SP is representing different situation in the estuary area. The SP1 is representing the plastic debris accumulation in the river end, SP2 is representing the plastic debris accumulation $250 \mathrm{~m}$ from the river end and SP3 is representing the plastic debris accumulation $500 \mathrm{~m}$ from the Wonorejo River end. For each SP, a total of 3 sub-sampling points were chosen randomly to obtain data in triplicate [17]. The sampling points of this research are presented on Figure 1.

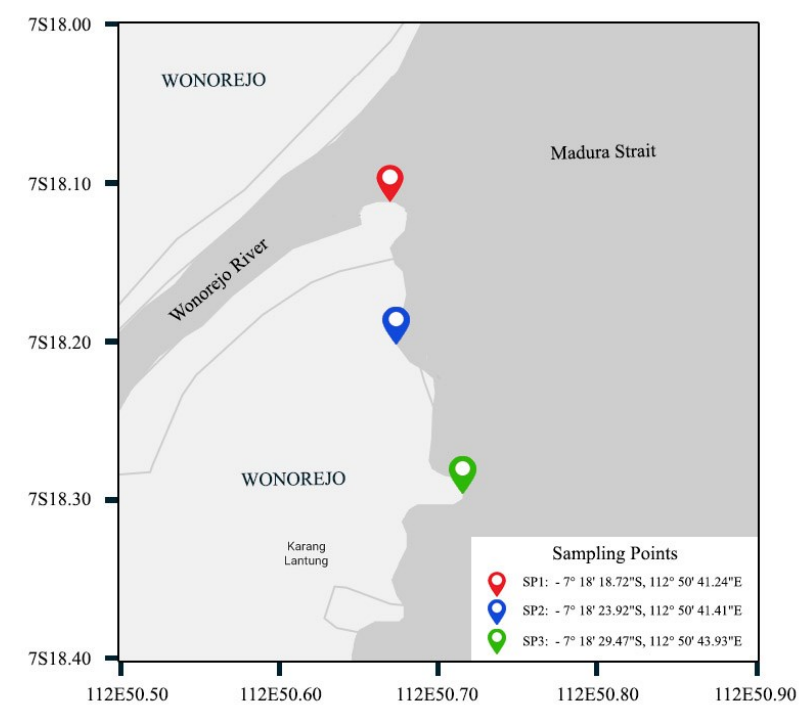

Fig. 1. Sampling Points.

\subsection{Collection of Sample}

All samples were collected around August to September 2018, during the dry season in Indonesia. Since Wonorejo Estuary is categorized as diurnal type of tidal characteristic, sampling was carried out during the high seawater level of Madura Strait (11 a.m. - 2 p.m. local time) to obtain higher accumulation of plastic debris on the seashore $[15,18]$. Sampling was manually collected (for big plastic debris) and using $5 \mathrm{~mm}$ pore cloth nets (for small plastic debris) inside the $50 \times 50 \mathrm{~cm}$ quadrant for each sub-sampling point. Collected Plastic Debris (CPD) were then stored inside the Polypropylene (PP) sealable containers.

All CPD were rinsed using seawater until there is no visible dirt. After cleaning the samples, all CPD were then soaked and gently stirred inside the seawater (temperature of 27.5 to $30{ }^{\circ} \mathrm{C}$ and salinity of 30 to 35 ppt) to promote floatation and distinguishing it from non-plastic debris [19]. Density of seawater used in this stage were ranged from $1,019.4$ to $1,022.6 \mathrm{~kg} / \mathrm{m}^{3}$. The used seawater density limits the floatation of CPD higher than $1,022.6 \mathrm{~kg} / \mathrm{m}^{3}$. Because of this reason, high density plastic like polyethylene terephthalate (PETE) and polyvinyl chloride (PVC) cannot be floated. The PETE and PVC were distinguished based on the physical characteristics of these plastic types [20]. The separation of PETE and PVC was highly limited to the capability of the researcher to distinguish it from other plastic types and impurities. The supernatant obtained from floatation procedure was repeatedly filtered using $5 \mathrm{~mm}$ pore cloth nets until there is no visible CPD retained on the filter. All filtered CPD were then stored inside sealable PP container for further analysis [21].

\subsection{Measurement of Collected Plastic Debris}

All CPD were dried using oven (Ogawa Seiki, Japan) under $70{ }^{\circ} \mathrm{C}$ temperature for 24 hours. The dried CPD were weighed using digital scale (Kenko, Indonesia). All CPD were grouped into 7 major plastic types based on its density i.e. low-density polyethylene (LDPE), highdensity polyethylene (HDPE), polystyrene (PS), polypropylene (PP), polyvinyl chloride (PVC), polyethylene terephthalate (PETE), and others. The density-based grouping was performed based on the plastic labels, common visual characteristics and the plastic density referring to the table provided in [15] and density measurement method in [22]. All CPD also grouped into 8 different group based on its original use of product namely plastic bag, fibrous plastic (rope and fabric items), water bottle (reusable and non-reusable items), bottle cap, food packaging (including PS-based items), cigarette butt, rubber and other.

\subsection{Statistical Analysis}

The statistical analysis for this research was performed with Minitab application version 18.1 [17,23,24]. Kolmogorov-Smirnov method was performed to analyse the data distribution, resulting in the normally distributed data. The correlation between SP and CPD was analysed using One-way Analysis of Variance (ANOVA). Further analysis of data significance was performed using Tukey's HSD method $[25,26]$. The statistical conclusion was determined according to the comparison of $p$-value under $95 \%$ of confidence intervals $(\alpha=0.05)$ [27,28].

\section{Results and Discussion}

The total of CPD from each SP is showed on Figure 2. Total CPD from SP1 was $126.07 \pm 12.00 \mathrm{~g} / \mathrm{m}^{2}$, from SP2 was $375.97 \pm 16.72 \mathrm{~g} / \mathrm{m}^{2}$ and from SP3 was $291.13 \pm 36.28$ $\mathrm{g} / \mathrm{m}^{2}$. The amount of CPD is presumed to be the highest accumulation in dry season since sampling were conducted during the high tide period of the Madura Strait seawater level. The high tide of seawater level will bring some floating materials back to the shoreline, resulting in the higher deposition of plastic debris in the 
estuary as the first contact of the river with the ocean ecosystem [15].

According to Figure 2, the amount of CPD from SP1 was significantly lower than both SP2 and SP3 $(p<0.05)$. This result is highly correlated to the characteristics of sampling point. Lower CPD in SP1 was obtained because of the Wonorejo River stream in the river mouth area. The stream of Wonorejo River that flowing towards Madura Strait forced the floating material to flow along with its direction, thus lowering the plastic tendency to be accumulated near the river mouth area [15].

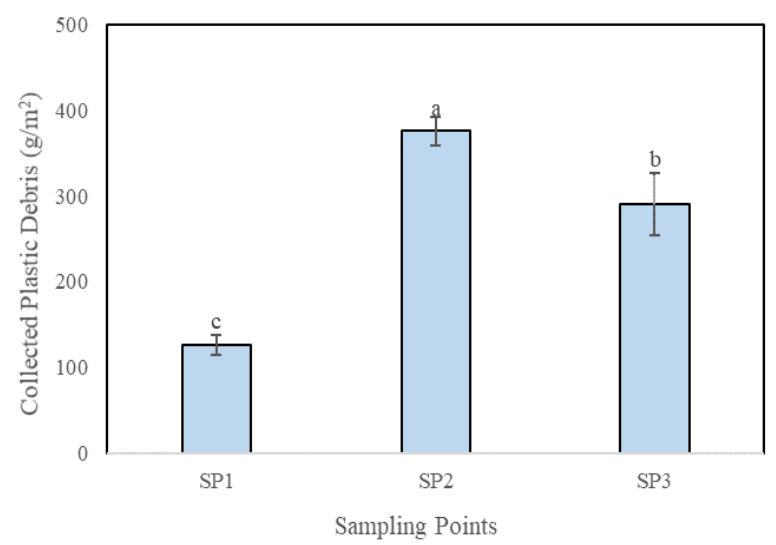

Fig. 2. Total CPD from each SP. Values are presented in Mean $\pm \mathrm{SD}(\mathrm{n}=3)$. Different letter above graph $(\mathrm{a}, \mathrm{b}, \mathrm{c})$ indicating significant differences of CPD from different SP.

Figure 2 also showed that the amount of CPD from SP2 was significantly higher compared to the other SP $(p<0.05)$. Based on Figure 1, the SP2 is located in the small basin area of Wonorejo River estuary. The significantly higher CPD from SP2 was obtained due to the geographical location effect that prevent the accumulated material to be distributed horizontally along the sea shoreline [29]. The geographical structure of SP2 creates a trap for accumulated debris resulting in higher CPD. The distribution of CPD based on its type (density) and original use in each SP are depicted on Figure 3 and Figure 4.

Based on Figure 3, the amount of collected PVC and PETE was very small. This case was occurred due to the limited capability of the researchers in distinguish it from other plastic types and impurities. The distribution of CPD type from all SP was quite similar. In all SP, the highest CPD type was LDPE, reaching up to 72.30, 73.13 and $72.60 \%$ from the SP1, SP2 and SP3, respectively. The second most abundant plastic type was PP with the percentage of 15.10, 17.20 and $17.22 \%$ from SP1, SP2 and SP3, respectively. The third most abundant percentage of plastic type was PS with 3.20 to $7.55 \%$, while the other types (HDPE, PETE, PVC and others) were collected in a small amount. Related to the Figure 4, the major contribution of LDPE debris were plastic bags, water bottles and food packaging items, while PP was obtained from the bottle cap items. The thin and light characteristics of LDPE create a floating tendency that lead to the send-back by ocean waves and deposition of the LDPE-based items into the sea shoreline $[10,30,31]$.

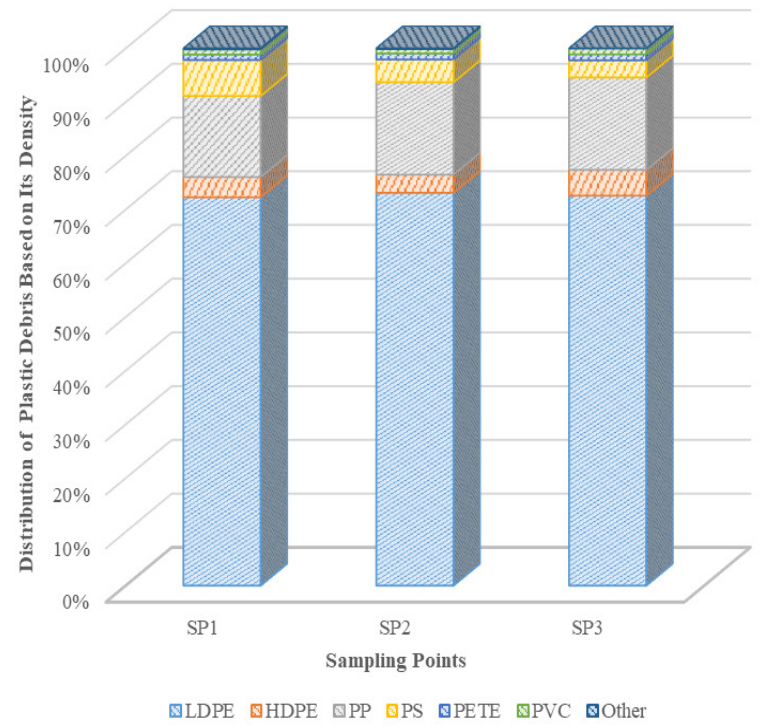

Fig. 3. Distribution of CPD based on its type.

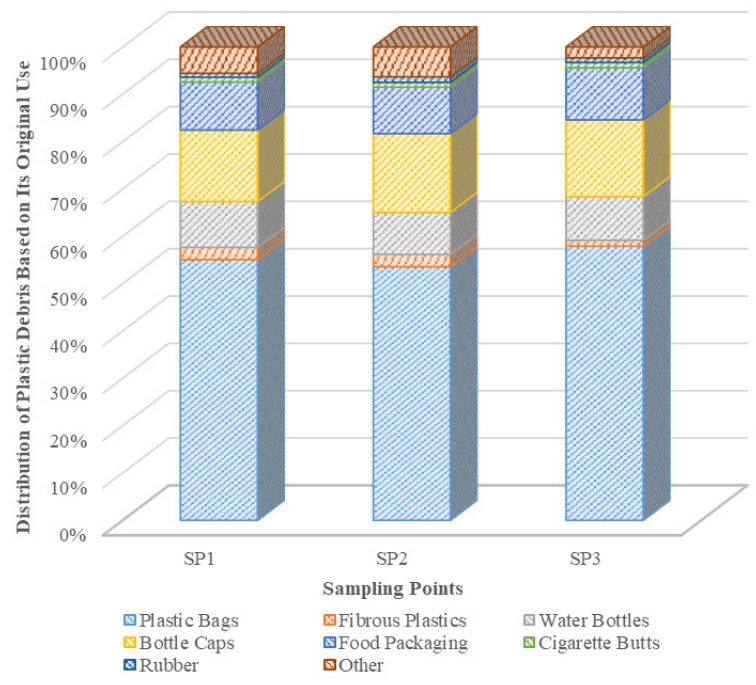

Fig. 4. Distribution of CPD based on its original use.

In accordance with the distribution of plastic debris based on its type, the distribution of plastic debris based on its original use in all SP was also quite similar. Based on Figure 4, it can be concluded that plastic bag is the major threat for the ecosystem of Wonorejo River estuary. The amount of collected plastic bags from SP1, SP2 and SP3 reaching up to $55.07 \%, 53.57 \%$, and $57.90 \%$, respectively. The second most polluting plastic item was bottle caps $(15.10 \%, 16.65 \%, 16.22 \%$ for SP1, SP2 and SP3, respectively), while food packaging and water bottles are following at the $3^{\text {rd }}$ and $4^{\text {th }}$ position (up to $11.02 \%$ and $9.68 \%$, respectively). Plastic bags, food packaging and water bottles are usually made from LPDE while bottle caps were made from PP. Based on the obtained result, the distribution of plastic based on its 
original use is highly correlated with the distribution of plastic type based on its density.

Since regulations related to the plastic pollution are currently being established in many countries, there is no legal standard to compare and/or determine the level of the pollution [32]. As a comparison, the amount of macroplastic found in Southeast China Bay was $126.9 \pm 95.4 \mathrm{~g} / \mathrm{m}^{2}$ with PE, PS and PP dominating the composition [33]. In Selayar Beach, South Sulawesi, Indonesia, the CPD reaching up to $4,978.3 \mathrm{~g} / \mathrm{m}^{2}$ [34]. In Japanese and Russian Beaches, CPD were in average of 2,144 and $1,344 \mathrm{~g} / \mathrm{m}^{2}$, respectively [35]. In accordance with our findings, Winton (2019) also reporting that plastic bags and food packaging were majoring the composition of plastic debris in rivers and lakes [36].

Please take a note that this research was conducted in Indonesia as one of the developing countries. Different tendency in the amount and the distribution of CPD may be acquired in different countries due to the different plastic usage regulation and plastic waste handling. This obtained result is considered to be the comparison of plastic debris accumulation in another diurnal type of the river estuary. Further studies in terms of upstream plastic waste usage and handling will highly support and enhance this obtained result [37,38]. Mapping of the distribution of plastic waste in the coastal area may also contribute to the clean-up strategies and plastic-pollution-related actions and strategies to be taken in the future [39-41].

\section{Conclusion}

The presented result confirms that Wonorejo River estuary is currently becoming one of the spots of plastic debris accumulation in Indonesia. The highest amount of collected plastic debris reaching up to $1162.37 \pm 84.60$ $\mathrm{g} / \mathrm{m}^{2}$. The most abundant plastic type was LDPE, contributed up to $73.13 \%$ of the collected plastic debris, followed by PP up to $17.22 \%$. The most polluting plastic item based on its original use that found to be abundant in Wonorejo River estuary was plastic bags (up to $57.90 \%$ ), followed by bottle caps (up to $16.65 \%$ ) and food packaging items (up to $11.02 \%$ ). Sampling location is significantly affecting the accumulation of plastic debris in the Wonorejo River estuary $(p<0.05)$, while the distribution of plastic debris based on its type was highly correlated with the distribution based on its original use items. The result of this initial analysis might be used as consideration and reference in conducting advance research and setting further actions to solve the plastic pollution problem in the marine ecosystem.

\section{References}

1. M. Haward, Nat. Commun. 9, 667 (2018)

2. M. Smith, D. C. Love, C. M. Rochman, and R. A. Neff, Curr. Environ. Heal. Reports 5, 375 (2018)

3. N. J. Diepens and A. A. Koelmans, Environ. Sci. Technol. 52, 8510 (2018)

4. L. G. A. Barboza, A. Dick Vethaak, B. R. B. O.
Lavorante, A. K. Lundebye, and L. Guilhermino, Mar. Pollut. Bull. 133, 336 (2018)

5. J. Wang, L. Zheng, and J. Li, Waste Manag. Res. 36, 898 (2018)

6. B. Nguyen, D. Claveau-Mallet, L. M. Hernandez, E. G. Xu, J. M. Farner, and N. Tufenkji, Acc. Chem. Res. 52, 858 (2019)

7. L. M. Hernandez, N. Yousefi, and N. Tufenkji, Environ. Sci. Technol. Lett. 4, 280 (2017)

8. C. Guerranti, T. Martellini, G. Perra, C. Scopetani, and A. Cincinelli, Environ. Toxicol. Pharmacol. 68, 75 (2019)

9. C. M. Rochman, S. M. Kross, J. B. Armstrong, M. T. Bogan, E. S. Darling, S. J. Green, A. R. Smyth, and D. Veríssimo, Environ. Sci. Technol. 49, 10759 (2015)

10. A. Emblem, Packag. Technol. Fundam. Mater. Process. 287 (2012)

11. P. Villarrubia-Gómez, S. E. Cornell, and J. Fabres, Mar. Policy 96, 213 (2018)

12. M. Sigler, Water. Air. Soil Pollut. 225, (2014)

13. M. Thiel, G. Luna-Jorquera, R. Álvarez-Varas, C. Gallardo, I. A. Hinojosa, N. Luna, D. Miranda-Urbina, N. Morales, N. Ory, A. S. Pacheco, M. Portflitt-Toro, and C. Zavalaga, Front. Mar. Sci. 5, (2018)

14. A. L. Andrady, Mar. Anthropog. Litter 29 (2015)

15. S. B. Kurniawan and M. F. Imron, Environ. Technol. Innov. 15, 100420 (2019)

16. S. B. Kurniawan and M. F. Imron, Environ. Technol. Innov. 16, (2019)

17. M. F. Imron, S. B. Kurniawan, and A. Soegianto, J. Environ. Manage. 241, 113 (2019)

18. A. Cózar, M. Sanz-Martín, E. Martí, J. I. González-Gordillo, B. Ubeda, J. Á.gálvez, X. Irigoien, and C. M. Duarte, PLoS One 10, (2015)

19. R. L. Coppock, M. Cole, P. K. Lindeque, A. M. Queirós, and T. S. Galloway, Environ. Pollut. 230, 829 (2017)

20. P. K. Cheung, L. T. O. Cheung, and L. Fok, Sci. Total Environ. 562, 658 (2016)

21. L. Fok and P. K. Cheung, Mar. Pollut. Bull. 99, 112 (2015)

22. T. Banas, Sciencing (2017)

23. H. S. Titah, I. F. Purwanti, B. V. Tangahu, S. B. Kurniawan, M. F. Imron, S. R. S. Abdullah, and N. 'Izzati Ismail, J. Environ. Manage. 238, 194 (2019)

24. M. F. Imron, S. B. Kurniawan, and H. S. Titah, Environ. Technol. Innov. 14, 100368 (2019)

25. I. F. Purwanti, S. B. Kurniawan, N. 'Izzati Ismail, M. F. Imron, and S. R. S. Abdullah, J. Environ. Manage. 249, 109412 (2019)

26. S. B. Kurniawan, I. F. Purwanti, and H. S. Titah, J. Ecol. Eng. 19, 154 (2018)

27. I. F. Purwanti, S. B. Kurniawan, and M. F. Imron, Environ. Technol. Innov. 15, 100422 (2019)

28. I. F. Purwanti, S. B. Kurniawan, and D. Simanjuntak, J. Ecol. Eng. 20, 135 (2019)

29. G. Signa, C. D. Tramati, and S. Vizzini, Mar. Ecol. Prog. Ser. 479, 13 (2013) 
30. B. Gewert, M. M. Plassmann, and M. Macleod, Environ. Sci. Process. Impacts 17, 1513 (2015)

31. B. M. Kyaw, R. Champakalakshmi, M. K. Sakharkar, C. S. Lim, and K. R. Sakharkar, Indian J. Microbiol. 52, 411 (2012)

32. B. Garcia, M. M. Fang, and J. Lin, Chinese J. Environ. Law 3, 11 (2019)

33. W. Yao, D. Di, Z. Wang, Z. Liao, H. Huang, K. Mei, R. A. Dahlgren, M. Zhang, and X. Shang, Mar. Pollut. Bull. 149, 110636 (2019)

34. R. Hermawan, A. Damar, and S. Hariyadi, IPB Univ. (2018)

35. T. Kusui and M. Noda, Mar. Pollut. Bull. 47, 175 (2003)

36. D. J. Winton, L. G. Anderson, S. Rocliffe, and S. Loiselle, Sci. Total Environ. 135242 (2019)

37. M. Eriksen, L. C. M. Lebreton, H. S. Carson, M. Thiel, C. J. Moore, J. C. Borerro, F. Galgani, P. G. Ryan, and J. Reisser, PLoS One 9, (2014)

38. F. Galgani, Front. Mar. Sci. 2, (2015)

39. I. Blanco, R. V. Loisi, C. Sica, E. Schettini, and G. Vox, Resour. Conserv. Recycl. 137, 229 (2018)

40. G. Vox, R. V. Loisi, I. Blanco, G. S. Mugnozza, and E. Schettini, Agric. Agric. Sci. Procedia 8, 583 (2016)

41. D. Briassoulis, E. Babou, M. Hiskakis, G. Scarascia, P. Picuno, D. Guarde, and C. Dejean, Waste Manag. Res. 31, 1262 (2013) 